\title{
Validating the Use of Heart Rate Variability for Estimating Energy Expenditure
}

\author{
AH Robertson ${ }^{1,2, *}$, K King ${ }^{1}$, SD Ritchie ${ }^{1,2}$, AP Gauthier ${ }^{1}$, M Laurence ${ }^{1}$, SC Dorman ${ }^{1,2}$ \\ ${ }^{1}$ School of Human Kinetics. Laurentian University, Canada \\ ${ }^{2}$ Centre for Research in Occupational Safety and Health (CROSH), Canada
}

Copyright $(\subset 2015$ by authors, all rights reserved. Authors agree that this article remains permanently open access under the terms of the Creative Commons Attribution License 4.0 International License

\begin{abstract}
The ability to measure free-living and activity-specific energy expenditure (EE) is useful for a variety of purposes. Heart rate variability (HRV) monitoring is emerging as a means for estimating $\mathrm{EE}$ and other physiological measures. The purpose of this study was to assess the accuracy of HRV-derived EE across a range of physical intensities and during free-living. Participants $(\mathrm{n}=30)$ completed two treadmill tests (walk and $\mathrm{VO}_{2 \max }$ ) measuring EE via Indirect Calorimetry (IC) and with the FirstBeat Bodyguard HRV monitor. Participants also wore the HRV monitors continuously for four consecutive days under free-living conditions. During the walk test, HRV-EE estimates across analysis conditions correlated moderately with IC estimates of EE $(\mathrm{r}=0.60-0.75 ; \mathrm{p}<0.05)$. During $\mathrm{VO}_{2 \max }$ testing, HRV-EE estimates across analysis conditions correlated strongly with IC estimates of EE with $(\mathrm{r}=0.85-0.98 ; \mathrm{p}<0.05)$. During free-living conditions, daily average and 4-day total HRV-EE estimates across all analysis conditions correlated strongly $(r=0.75-0.98 ; \mathrm{p}<0.05)$. HRV-EE estimation improves as activity-intensity increases. HRV-EE estimates improve further with the addition of IC-measured $\mathrm{HR}_{\max }$ and $\mathrm{VO}_{2 \max }$, particularly at low intensities; however, meaningful differences were not seen between values when considering group means. HRV-EE estimates are sufficiently accurate to indicate this method possesses practical utility and may be used for individual EE monitoring.
\end{abstract}

Keywords Heart Rate Variability, Indirect Calorimetry, Maximum Heart Rate, $\mathrm{VO}_{2 \max }$, Activity Intensity

\section{Introduction}

The ability to assess an individual's energy expenditure (EE) is useful in a multitude of athletic-, lifestyle-, and health-related scenarios. For athletes performing intense training on a daily basis, EE monitoring can provide valuable information to optimize energy intake and training duration, intensity, and frequency to promote peak performance while avoiding overtraining. Individuals with inactivity-related health issues, or those seeking to improve their health, can also benefit from daily EE monitoring by tracking physical activity patterns and tailoring energy intake accordingly. However, EE monitoring can only be beneficial if the chosen method of measurement is reliable and accurate.

Generally, EE assessment can be accomplished using several different methods of measurement and analysis including: direct (DC) and indirect (IC) calorimetry, doubly labelled water (DLW), heart-rate (HR), accelerometers, activity diaries and most recently, heart-rate variability monitors. DC and IC are considered the most accurate methods of assessment [3, 12, 13], however they require costly laboratory equipment and expertise. Doubly labelled water is the most accurate free-living assessment of EE, however this method is only capable of measuring block-periods of EE (e.g. 48h), does not allow for activity-specific EE analysis and is not readily accessible for use $[2,3]$. Accelerometers and activity diaries are the least expensive methods, but their accuracy in field studies has been questioned $[3,9,11]$.

The use of HR devices for estimating EE has become mainstream in the last decade, particularly for use in athletes, both professional and amateur. The added advantages of these devices are that they allow for free-living data collection and the determination of activity-specific EE while being more cost-effective than IC, DC and DLW, and more accurate than accelerometers or diary records [9]. This is based upon the linear relationship between heart rate and kilocalorie expenditure at sub-maximal exercise intensity, making HR measurement a good surrogate measure for EE estimation $[2,5,14]$. Adding to the appeal and versatility of HR-based EE estimation is the ability to obtain reasonably accurate EE measurements without the need for individual calibration of the monitoring device. Rennie, et al. [16] compared EE values obtained from HR monitoring of subjects over 4-days and found that the values obtained with and without individual device calibration were highly correlated. The ability to obtain accurate EE measures 
without the need for device calibration, beyond inputting basic personal informtion (age, height, weight, activity level), is appealing because the testing necessary to obtain the measures for full device calibration (i.e. maximal $\mathrm{HR}\left(\mathrm{HR}_{\max }\right)$ and maximal oxygen consumpation $\left.\left(\mathrm{VO}_{2 \max }\right)\right)$ requires an individual to exercise at high intensity and may be contra-indicated for individuals with existing health concerns.

To date, studies have shown over-estimation of EE using traditional HR methods in comparison to gold-standard measures [5, 7]. To address this, FirstBeat Technologies Ltd. [8] (among others) developed a Heart Rate Variability (HRV) monitor and analysis software. This device acts like an electrocardiogram, continuously recording the variation of beat-to-beat intervals, also known as R-R intervals. The FirstBeat Software developed for use with this device then utilizes the HRV data, as well as information about respiration rate and $\mathrm{On} / \mathrm{Off}$ response kinetics of $\mathrm{VO}_{2}$ derived from R-R-interval, to estimate EE [8]. This is more accurate than HR estimation alone [14].

HRV measurement has the additional benefit of being able to provide information regarding parasympathetic and sympathetic nervous system input on HR, and it can be used to extrapolate information regarding disease risk, stress, recovery, activity intensity, training effect, and energy expenditure $[1,2,8,18]$. These applications hold promise for extended use of these devices, (i.e. outside of sport) in free-living conditions; specifically for more health-related monitoring.

Montgomery et al. [14] first investigated the accuracy of the HRV system, using data obtained from a Suunto HR device analyzed in Firstbeat Technologies software, to estimate EE compared to IC during sub-maximal and maximal intensity exercise on a treadmill. Their study showed improvement of EE estimation across the three levels of analysis at moderate to high intensities compared to HR estimations, however all analyses showed an underestimation of the EE compared to IC. They argued that accuracy is primarily lost at maximal intensities and that inputting measured maximal $\mathrm{HR}$ and $\mathrm{VO}_{2 \max }$ significantly improved accuracy. This particular study however focused solely on trained athletes and only evaluated EE derived from the HRV data against IC at moderate-to-high intensity activity.

To date, investigation of HRV-based EE estimation in comparison to IC during low intensity activity and daily living in non-athlete participants has never been done. Considering the potential applications of the FirstBeat Bodyguard, the accuracy and performance of the device across a full range of physical intensities needs to be studied in order to validate its accuracy and in turn its use as a practical tool for estimation of EE in a variety of settings and contexts.

For the benefits of EE monitoring to be applied within the general population for the purposes of exercise prescription, health maintenance, physical capacity assessment, and activity monitoring, it is crucial that the device used be: user-friendly, mobile, and comfortable under every-day living conditions. Additionally, it should be capable of individual-calibration, based on estimates, without the need for gold standard laboratory measures, specifically for $\mathrm{VO}_{2 \max }$, or $\mathrm{HR}_{\max }$, while still providing accurate $\mathrm{EE}$ measurements. An important consideration for the expanded use of this technology is whether or not it is necessary to obtain measured maximum/minimum Heart Rate (HR) and maximum oxygen consumption $\left(\mathrm{VO}_{2 \max }\right)$ values in order to individually calibrate the device and software for EE calculation. These two measures require the subject to exercise at increasing intensities (often on a treadmill) until exhaustion. Due to these requirements they maintain an inherent level of risk, specifically for a heart attack, and therefore are only performed in clinical or laboratory settings. Even under these conditions, some people would be excluded from performing these tests as a precaution. However, using less invasive means, we can estimate an individual's $\mathrm{HR}_{\max }$ and $\mathrm{VO}_{2 \max }$. $\mathrm{EE}$ has been found to be reasonably estimated without individual calibration of HR monitoring devices [16], however it has yet to be determined if individual calibration using measured $\mathrm{HR}_{\max }$ and $\mathrm{VO}_{2 \max }$ is a necessity for accurate EE measurement using the Firstbeat Bodyguard HRV device and analysis software. EE monitoring during physical activity and daily-living, in conjunction with dietary caloric restriction, is a useful tool for achieving weight loss and long-term maintenance of a healthy weight [6] but it is important to ensure that a device chosen for this and related purposes does not provide inaccurate EE estimates.

Therefore, the purpose of this study is threefold: i) to compare the EE estimates of the FirstBeat HRV monitor during low intensity exercise (i.e. 30 minute walking) with EE measured using Indirect Calorimetry; ii) to compare the EE estimates of the FirstBeat HRV monitor during maximum intensity exercise (i.e. $\mathrm{VO}_{2 \max }$ test) with $\mathrm{EE}$ measured using Indirect Calorimetry; and iii) to compare EE estimates under conditions of daily living, as calculated using measured (with Indirect Calorimetry) versus estimated (standard estimates and FirstBeat measured estimates) of $\mathrm{HR}_{\max }$ and $\mathrm{VO}_{2 \max }$.

\section{Materials and Methods}

\section{Participants}

Thirty adult participants consented to be involved in this study. All were healthy, non-smoking and non-elite athletes. Participants were screened using the PAR-Q [4] and a general Health Status form to assess their capacity to safely perform a $\mathrm{VO}_{2 \max }$ test. If any contraindications were identified on either form, the participant was excluded from the study; however no one was excluded for this reason. During laboratory testing and analysis, 6 participants were removed from the study due to missing HRV data during the low intensity and/or maximum intensity treadmill testing, resulting in a total of 24 participants (12 females, 12 males). 
Missing data resulted from detachment of the electrode due to excess sweat as well as from loss of connection between the electrode cables and the HRV data logger.

Upon completion of the laboratory testing, the participants continued wearing the HRV monitors for an additional four days of data collection. Seventeen participants ( 10 females, 7 males) returned the devices with four full days of data that were available for analysis. The other 13 participants either had large gaps in their HRV data due to periodic device removal, or they did not return the devices with four full days of data; therefore they were not included in the free-living data analysis. This study received approval from the Laurentian University Research Ethics Board and all participants provided written consent prior to commencing the study.

\section{Laboratory Study Design}

Participants visited the laboratory once for approximately 90-minutes. Preliminary test measures were taken: age, height, weight, and resting heart rate $\left(\mathrm{HR}_{\mathrm{rest}}\right)$. After this, each participant completed two consecutive treadmill-based tests, separated by a 2-minute break: 1) a 30-minute, low intensity walk test; and 2) a high intensity, maximal oxygen consumption $\left(\mathrm{VO}_{2 \max }\right)$ test. Participants wore the FirstBeat Bodyguard heart rate variability (HRV) monitors, as per manufacturer instructions, throughout testing as well as having their oxygen consumption continuously measured using a SensorMedics Vmax-29c metabolic cart.

Maximum heart rate $\left(\mathrm{HR}_{\max }=\right.$ beats per minute) was calculated by two methods: i) estimated $\mathrm{HR}_{\max }$ using Tanaka et al. [17] $\left(208-\left(0.7^{*}\right.\right.$ age $\left.=\mathrm{HR}_{\max }\right)$; and ii) measured $\mathrm{HR}_{\max }$ via the FirstBeat Bodyguard 2 during the high intensity test $\left(\mathrm{HR}_{\max }\right)$.

Maximal oxygen consumption $\left(\mathrm{VO}_{2 \max }=\mathrm{ml} / \mathrm{kg} / \mathrm{min}\right)$ was calculated through two methods: i) estimation using fitness activity classifications $(0-10)$ as described in the FB Sport Software program $\left(\mathrm{VO}_{2 \operatorname{maxFB}}\right)$; and ii) measured using the SensorMedics Vmax-29c metabolic card during the high intensity test $\left(\mathrm{VO}_{2 \operatorname{maxIC}}\right)$.

Using various combinations of these measures, EE values were compared across four conditions: i) obtained from IC measures $\left(\mathrm{EE}_{\mathrm{IC}}\right)$ - walk test and high intensity tests only; ii) obtained from the FirstBeat SPORT (FB) software using estimated $\mathrm{HR}_{\max }$ and activity class $\left(\mathrm{EE}_{1}\right)$; iii) obtained from the FB software using measured $\mathrm{HR}_{\max }$ and $\mathrm{VO}_{2 \operatorname{maxFB}}\left(\mathrm{EE}_{2}\right)$; and iv) obtained from the $\mathrm{FB}$ software using measured $\mathrm{HR}_{\max }$, and $\mathrm{VO}_{2 \operatorname{maxIC}}\left(\mathrm{EE}_{3}\right)$. Table I summarizes the four different comparison conditions of measuring or estimating EE.

Table 1. Comparison conditions for measuring and estimating EE

\begin{tabular}{|c|c|}
\hline Variable & Description \\
\hline $\mathrm{EE}_{\mathrm{IC}}$ & Output from indirect calorimetry \\
\hline $\mathrm{EE}_{1}$ & FB software w/ age-predicted $\mathrm{HR}_{\max }$ and activity level \\
$(0-10)$
\end{tabular}

\section{0-minute Low-intensity Test}

The participants walked at a speed that was set such that it would elicit a heart rate of between $20-39 \%$ of the participant's heart rate reserve (Target HR $\left.=\% *\left(\mathrm{HR}_{\max }-\mathrm{HR}_{\text {rest }}\right)+\mathrm{HR}_{\text {rest }}\right)$, which is indicative of a light-intensity exercise [15]. This information was established for each individual participant in advance of the testing and monitored for the duration of the testing by a member of the research team through the use of a Polar FT7 HR monitor. Following the low-intensity treadmill test, the participant was given a two-minute break prior to commencing a $\mathrm{VO}_{2 \max }$ test.

$\mathrm{VO}_{2 \max }$ Test

As described in the Physiology of Exercise (1984) and outlined here, the participant started with a 5-minute warm-up at a moderate walking speed with no gradient. The test was performed in stages of 2-minutes, with speed and/or gradient increasing at the beginning of each successive stage. Each 2-minute stage length provided sufficient time to attain steady-state values. The increases in speed and gradient at each stage ranged from $0-1.5 \mathrm{mph}$ and $0-10 \%$ respectively. HR was recorded throughout the procedure using the Polar FT7 HR monitor as a safety precaution, to ensure heart rate remained below each participant's estimated maximum heart rate as previously indicated. The test continued until $\mathrm{VO}_{2}$ consumption plateaued with increasing exercise intensity indicating the limit at which no further increase in oxygen consumption can occur [10]. Once the exercise test was voluntarily terminated due to exhaustion, the speed and gradient on the treadmill was reduced to a walking speed with no gradient, for a five-minute cool-down period. Multiple members of the research team were present throughout the test to ensure the safety of the participants.

\section{Daily Free-living}

Participants that wore the HRV device for the extended data-logging period did so commencing after the laboratory session. The devices were worn continuously, except when removed for hygiene purposes and to replace electrodes. Following four consecutive days of wear, participants returned the devices to a member of the research team.

\section{Data Analysis}

Data collected from the FirstBeat HRV monitors was imported into the FirstBeat SPORT computer software program for analysis. EE expenditure was calculated in four ways for the low and high intensity tests: i) $\mathrm{EE}_{\mathrm{IC}}$ (the gold standard), $\mathrm{EE}_{1}, \mathrm{EE}_{2}$ and $\mathrm{EE}_{3}$. During the 4-day wear period of Active Living Conditions, EE expenditure, was calculated in three ways: $\mathrm{EE}_{1}, \mathrm{EE}_{2}$ and $\mathrm{EE}_{3}$

All data was recorded as the mean plus/minus the standard error of the mean (SEM). The EE data from the metabolic cart $\left(\mathrm{EE}_{\mathrm{IC}}\right)$ was compared to EE calculated using data from the Firstbeat Bodyguard $2 \mathrm{HRV}$ devices analysed in the Firstbeat SPORT software under the aforementioned 
conditions: $\mathrm{EE}_{1}, \mathrm{EE}_{2}, \& \mathrm{EE}_{3}$. Bland Altman plots, created using SigmaPlot 13, indicated that the variance in the measures across all software analysis conditions tst was within a reasonable range $( \pm 2 \mathrm{SD})$ for further statistical analysis (Figures not shown). Paired t-tests, intraclass correlations, and descriptive statistics were used to detect meaningful differences and consistency between the measures. The EE data for each day of the 4-day free-living period was calculated using the Firstbeat SPORT software under the same conditions $\left(\mathrm{EE}_{1}, \mathrm{EE}_{2}, \& \mathrm{EE}_{3}\right)$ and compared collectively ( 17 participants $\mathrm{x} 4$ complete days of data $=68$ individual days of data). All statistical tests were performed using SPSS version 20.0 and significance was accepted at $\mathrm{p}<0.05$.

\section{Results}

Average age, height, and weight $( \pm \mathrm{SD})$ of the 24 participants with intact data for the laboratory tests were: $22 \pm 2.3$ years, $174 \pm 8.9 \mathrm{~cm}$, and $71 \pm 10.2 \mathrm{~kg}$ respectively.

$\mathrm{HR}_{\max }$ measured and predicted; and $\mathrm{VO}_{2 \max }$ values measured from FB and IC correlated modestly, but significantly (see Table II).

Table 2. Average measured (IC) and predicted (FB) values of participant laboratory testing ( $\mathrm{n}=24)$ using basic information for $\mathrm{HR}_{\max }$ and $\mathrm{VO}_{2 \max }$

\begin{tabular}{|l|l|l|l|l|l|l|}
\hline $\begin{array}{l}\mathrm{HR}_{\max P} \\
\mathrm{bpm} \pm \mathrm{SD}\end{array}$ & $\begin{array}{l}\mathrm{HR}_{\max M} \\
\mathrm{bpm} \pm \mathrm{SD}\end{array}$ & $\begin{array}{l}\text { Mean difference } \\
(\mathrm{bpm})\end{array}$ & $\%$ diff & SEM & $\mathrm{r}$ & $\mathrm{p}$ \\
\hline $193 \pm 1.6$ & $189 \pm 10.0$ & 4.08 & $2.1 \%$ & 1.93 & 0.441 & 0.031 \\
\hline
\end{tabular}

\begin{tabular}{|l|l|l|l|l|l|l|}
\hline $\begin{array}{l}\mathrm{VO}_{2 \max F B} \\
\mathrm{ml}^{-1} \mathrm{~kg}^{-1} \mathrm{~min} \pm \mathrm{SD}\end{array}$ & $\begin{array}{l}\mathrm{VO}_{2 \operatorname{maxlc}} \\
\mathrm{ml}^{-1} \mathrm{~kg}^{-1} \mathrm{~min} \pm \mathrm{SD}\end{array}$ & $\begin{array}{l}\text { Mean difference } \\
\left(\mathrm{ml}^{-1} \mathrm{~kg}^{-1} \mathrm{~min}\right)\end{array}$ & $\%$ diff & SEM & $\mathrm{r}$ & $\mathrm{p}$ \\
\hline $46.7 \pm 6.4$ & $46.1 \pm 7.6$ & 0.61 & $1.3 \%$ & 1.45 & 0.493 & 0.014 \\
\hline
\end{tabular}

$\mathbf{H R}_{\max }=$ estimated maximal heart rate using age-based equation

$\mathbf{H R}_{\mathbf{m a x M}}=$ measured maximal heart rate during the $\mathrm{VO}_{2 \max }$ test

$\mathbf{V O}_{2 \operatorname{maxFB}}=$ maximal oxygen consumption estimated by FirstBeat SPORT software during the $\mathrm{VO}_{2 \max }$ test

$\mathbf{V O}_{\text {2maxIC }}=$ maximal oxygen consumption measured by Indirect Calorimetry during the $\mathrm{VO}_{2 \max }$ test

$\mathbf{b p m}=$ beats per minute

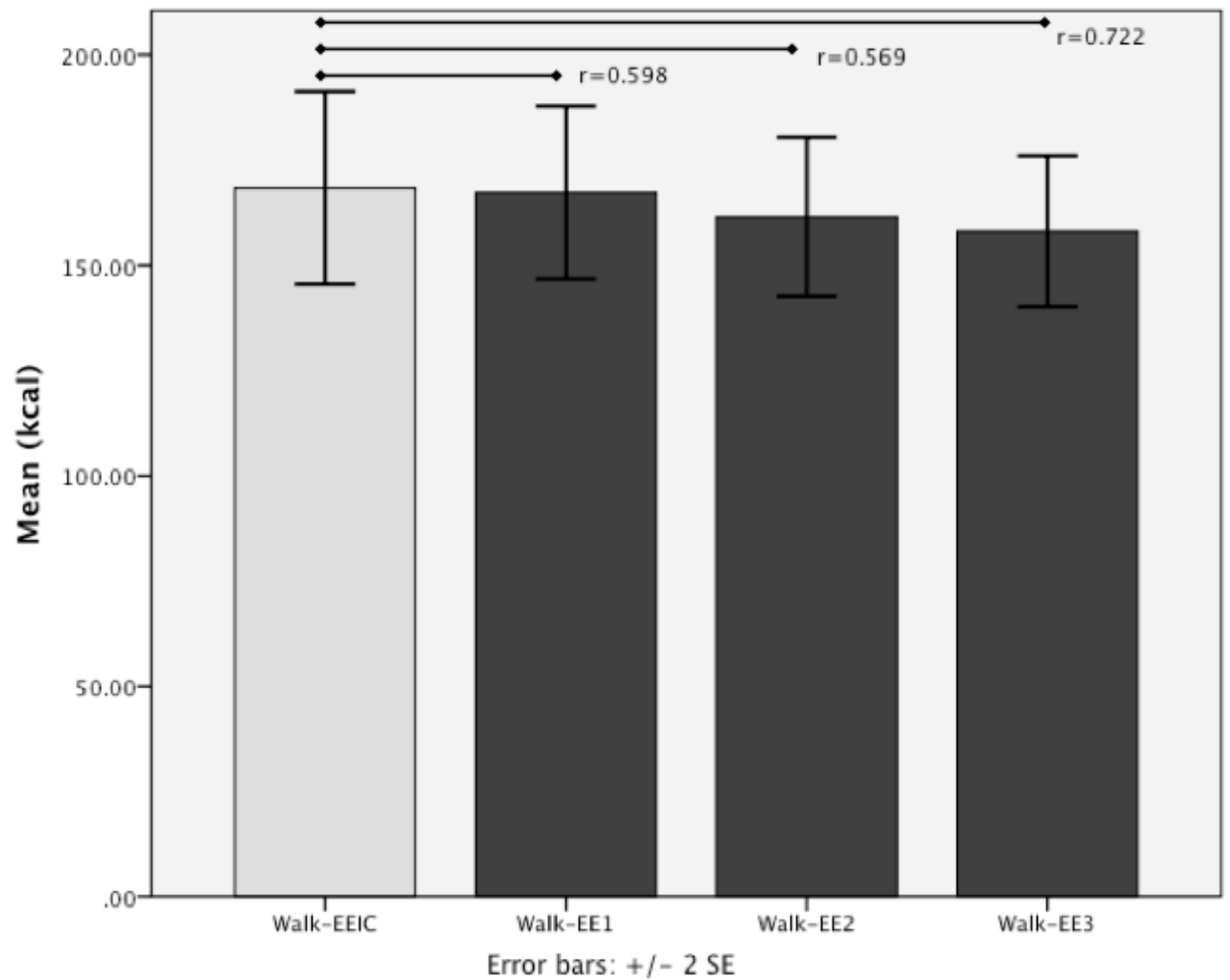

Figure 1. Average Kilocalorie expenditures during the low-intensity walk test as estimated by EEIC, EE1, EE2, and EE3 


\section{Low-intensity Walk Test}

During the 30 minute low-intensity test, average EE values $( \pm \mathrm{SE})$ were: $\mathrm{EE}_{\mathrm{IC}}: 168 \pm 11.4 \mathrm{kcal} ; \mathrm{EE}_{1}: 167 \pm 10.3 \mathrm{kcal}$; $\mathrm{EE}_{2}: 161 \pm 9.4 \mathrm{kcal}$; and $\mathrm{EE}_{3}: 158 \pm 8.9 \mathrm{kcal}$. Paired t-tests indicated no significant differences between $\mathrm{EE}_{\mathrm{IC}}$ and any of the FB analysis conditions.

EE $_{\text {IC }}$ correlated significantly $(\mathrm{p}<0.05)$ with all FB analysis conditions (see Figure 1). When comparing correlations amongst the three $\mathrm{FB}$ analysis conditions, $\mathrm{EE}_{\mathrm{IC}}$ correlated most closely with $\mathrm{EE}_{3}$ (see Figure 1).

\section{Maximum Intensity $\mathrm{VO}_{2 \max }$ Test}

In the maximum intensity $\mathrm{VO}_{2 \max }$ test, average EE values $( \pm \mathrm{SE})$ were: $\mathrm{EE}_{\mathrm{IC}}: 168 \pm 14.2 \mathrm{kcal} ; \mathrm{EE}_{1}: 178 \pm 14.7 \mathrm{kcal} ; \mathrm{EE}_{2}$ : $170 \pm 13.8 \mathrm{kcal}$; and $\mathrm{EE}_{3}: 168 \pm 13.7 \mathrm{kcal}$. Paired t-tests indicated no significant differences between $\mathrm{EE}_{\mathrm{IC}}$ and any of the FB analysis conditions.

$\mathrm{EE}_{\mathrm{IC}}$ correlated significantly $(\mathrm{p}<0.05)$ with all FB analysis conditions (see Figure 2). When comparing correlations amongst the three $\mathrm{FB}$ analysis conditions $\mathrm{EE}_{\mathrm{IC}}$ correlated most closely with $\mathrm{EE}_{3}$ (see Figure 2).

\section{Daily Free-living Energy Expenditure}

Average age, height, and weight of the participants with 4 full days of data ( $n=17,68$ total days) were: $22 \pm 2.6$ years, $172 \pm 9.3 \mathrm{~cm}$, and $68 \pm 9.5 \mathrm{~kg}$ respectively.

Measured and predicted $\mathrm{HR}_{\max }$ correlated weakly; and $\mathrm{VO}_{2 \max }$ values measured from $\mathrm{FB}$ and $\mathrm{IC}$ correlated moderately (see Table III).

During the four-day data collection period, average values for the individual sample days $( \pm \mathrm{SE})(n=68)$ were: $E_{1}$ : $2681 \pm 80.04 \mathrm{kcal} ; \quad \mathrm{EE}_{2}: 2626 \pm 73.57 \mathrm{kcal} ;$ and $\mathrm{EE}_{3}$ : $2568 \pm 68.45 \mathrm{kcal}$. Paired t-tests indicated significant differences between $\mathrm{EE}_{1} \& \mathrm{EE}_{2}(\mathrm{p}=0.001)$, and between $\mathrm{E}_{1}$ \& $\mathrm{EE}_{3} \quad(\mathrm{p}=0.011) . \quad \mathrm{EE}_{1}$ correlated significantly with $\mathrm{EE}_{2}$ $(r=0.983 ; p<0.0001)$ and $\mathrm{EE}_{3}(\mathrm{r}=0.844 ; \mathrm{p}<0.0001)$.

Four-day total values $( \pm \mathrm{SE})(\mathrm{n}=17)$ were: $\mathrm{EE}_{1}$ : $10,724 \pm 544.1 \mathrm{kcal} ; \mathrm{EE}_{2}: 10,506 \pm 491.2 \mathrm{kcal}$; and $\mathrm{EE}_{3}$ : $10,273 \pm 451.7 \mathrm{kcal}$. Paired t-tests indicated no significant differences between $\mathrm{EE}_{1} \& \mathrm{EE}_{2}(\mathrm{p}=0.061)$, nor between $\mathrm{EE}_{1}$ and $\mathrm{EE}_{3}(\mathrm{p}=0.198) . \mathrm{EE}_{1}$ correlated significantly with $\mathrm{EE}_{2}$ $(r=0.983 \mathrm{p}<0.0001)$ and $\mathrm{EE}_{3}(\mathrm{r}=0.788 ; \mathrm{p}<0.0001)$.

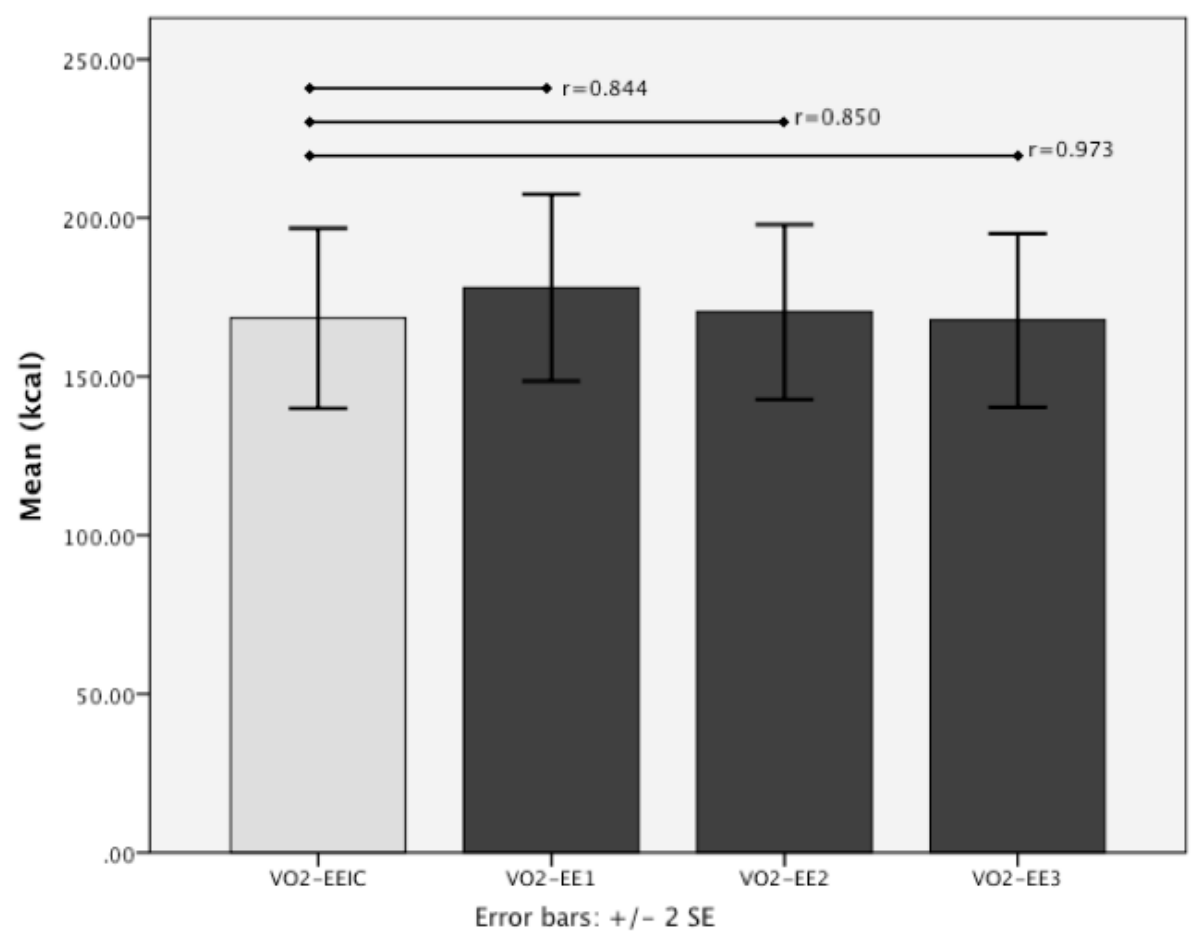

Figure 2. Average Kilocalorie expenditures during the maximum intensity $\mathrm{VO}_{2 \max }$ test as estimated by EEIC, EE1, EE2 and EE3.

Table 3. Average measured (IC) and predicted (FB) values of participant free-living ( $\mathrm{n}=17)$ using basic information for $\mathrm{HR}_{\max }$ and $\mathrm{VO}_{2 \max }$

\begin{tabular}{|l|l|l|l|l|l|l|}
\hline $\begin{array}{l}\mathrm{HR}_{\operatorname{maxP}} \\
\mathrm{bpm} \pm \mathrm{SD}\end{array}$ & $\begin{array}{l}\text { HR } \\
\mathrm{Bpm}\end{array}$ & $\begin{array}{l}\text { Mean difference } \\
(\mathrm{bpm})\end{array}$ & $\%$ diff & SEM & $\mathrm{r}$ & $\mathrm{p}$ \\
\hline $193 \pm 1.8$ & $189 \pm 9.0$ & 4.65 & $2.4 \%$ & 2.05 & 0.396 & 0.115 \\
\hline
\end{tabular}

\begin{tabular}{|l|l|l|l|l|l|l|}
\hline $\begin{array}{l}\mathrm{VO}_{2 \max B B} \\
\mathrm{ml}^{-1} \mathrm{~kg}^{-1} \mathrm{~min} \pm \mathrm{SD}\end{array}$ & $\begin{array}{l}\mathrm{VO}_{2 \operatorname{maxlc}} \\
\mathrm{ml}^{-1} \mathrm{~kg}^{-1} \mathrm{~min} \pm \mathrm{SD}\end{array}$ & $\begin{array}{l}\text { Mean difference } \\
\left(\mathrm{ml}^{-1} \mathrm{~kg}^{-1} \mathrm{~min}\right)\end{array}$ & $\%$ diff & $\mathrm{SEM}$ & $\mathrm{r}$ & $\mathrm{p}$ \\
\hline $46.1 \pm 6.3$ & $45.5 \pm 8.1$ & 0.59 & $1.3 \%$ & 1.75 & 0.514 & 0.035 \\
\hline
\end{tabular}




\section{Discussion}

The information that can be extrapolated from HRV monitoring is appealing for a variety of both clinical and athletic purposes. Therefore various groups including hospitals, sports teams, and researchers have begun implementing these devices for various causes, including energy expenditure monitoring.

Implementation within the general population has occurred with the elimination of laboratory measures of $\mathrm{VO}_{2 \max }$ and $\mathrm{HR}_{\max }$. Montgomery et al. [14] showed that these values are important in order to obtain accurate estimates, although this study was in a small population of elite athletes and during high intensity testing. In order to advocate for the use of HRV-based EE estimations outside of these limited circumstances, it is important to further examine its capabilities under more varied conditions and in non-elite athletes to better understand the accuracy of its outputs.

The FirstBeat SPORT software is capable of analyzing HRV data to obtain EE values using various levels of subject baseline information, each increasing in the level of information detail, which informed the decisions surrounding the particular levels of analysis that were chosen for comparison in this study. $\mathrm{EE}_{1}$ is the most basic level of analysis capable by the FirstBeat SPORT software and uses subject age, height, weight, $\mathrm{HR}_{\text {rest }}, \mathrm{HR}_{\max P}$, and activity level (0-10) to estimate $\mathrm{VO}_{2 \max }$ via the software's energy expenditure algorithm $\left(\mathrm{VO}_{2 \mathrm{maxFB}}\right)$. This level of analysis would be utilized in the event an individual is deemed physically unable to perform the testing required or does not have access to the equipment and personnel to obtain $\mathrm{HR}_{\text {max }}$ and $\mathrm{VO}_{2 \max }$ values. Thus, this level of analysis is of particular interest since it does not require any testing to be performed for individual device calibration; if, the EE estimates are sufficiently accurate in comparison to $\mathrm{IC}$. $\mathrm{EE}_{2}$ was the next level of analysis chosen for comparison to IC and substitutes $\mathrm{HR}_{\max P}$ with $\mathrm{HR}_{\max }$, as well as substitutes activity level with $\mathrm{VO}_{2 \operatorname{maxFB}} . \mathrm{EE}_{2}$ was selected based on the scenario wherein an individual is deemed capable of performing maximal exertion activity, but does not have access to the equipment required to obtain $\mathrm{VO}_{2 \max }$ from gold standard methods of measurement (i.e. indirect calorimetry). In this analysis condition, individual device calibration would be completed by the subject performing a maximum intensity test while wearing the device and obtaining $\mathrm{VO}_{2 \max \mathrm{B}}$ from a preliminary analysis of the $\mathrm{HRV}$ data (i.e. $\mathrm{EE}_{1}$ ). $\mathrm{EE}_{3}$ was the final level of analysis selected for comparison to IC and substitutes $\mathrm{VO}_{2 \max I C}$ for $\mathrm{VO}_{2 \text { maxFB }}$. This level of analysis uses participant information obtained from gold standard measures, and is therefore that which most closely replicates the IC analysis conditions using the FirstBeat SPORT software.

To determine whether EE derived from the various levels of HRV analysis is accurate compared to Indirect Calorimetry, intra-class correlations and bland-altman plots, paired t-tests, and descriptive statistics (mean and percentage differences) were used to look for meaningful differences and consistency between the methods of measurement. Correlation coefficients were interpreted as follows: $\mathrm{r}<0.35=$ low/weak correlation; $0.36<\mathrm{r}<0.67$ moderate correlation; $0.68<\mathrm{r} \leq 1.0=$ high/strong correlation [19].

A key purpose of this study was to establish whether or not it is necessary to obtain $\mathrm{HR}_{\max }$ and $\mathrm{VO}_{2 \max }$ baseline measures prior to the use of HRV devices to monitor individuals during free-living activity. This was necessary and important to determine since testing to obtain these values is invasive, costly and cannot be conducted in many at-risk populations. A moderate, but significant, correlation was found between measured and predicted $\mathrm{HR}_{\max }$ and $\mathrm{VO}_{2 \max }(\mathrm{r}=0.441 ; \mathrm{p}<0.05$ and $\mathrm{r}=0.493 ; \mathrm{p}<0.05$ respectively), and significant difference was found between measured and predicted $\mathrm{HR}_{\max }(\mathrm{p}=0.045)$, but not between estimates of $\mathrm{VO}_{2 \max }(\mathrm{p}=0.680)$, using paired t-tests. Interestingly, the difference in means between measured and predicted $\mathrm{HR}_{\max }$ and $\mathrm{VO}_{2 \max }$ values $(2.1 \%$ and $1.3 \%$ respectively) was minimal, indicating that estimation accuracy improves when considering groups of subjects. While the FirstBeat software does not predict $\mathrm{HR}_{\max }$ and $\mathrm{VO}_{2 \max }$ accurately enough on an individual level to justify substituting HRV-based estimations of these values for those from IC; estimation of $\mathrm{HR}_{\max }$ and $\mathrm{VO}_{2 \max }$ improves in relation to gold standard values at the group level.

In this study, we compared the use of HRV devices for energy expenditure estimation under three conditions: a low intensity walk test, a maximum intensity $\mathrm{VO}_{2 \max }$ test, and during extended conditions of daily free-living.

During low-intensity activity, underestimation of EE and moderately strong intra-class correlations were found using the FirstBeat software HRV analysis in comparison to gas-exchange EE estimations (see Figure 1). While the baseline level of HRV analysis $\left(\mathrm{EE}_{1}\right)$ was found to only correlate moderately with $\mathrm{EE}_{\mathrm{IC}}(\mathrm{r}=0.598)$, the strength of the correlation did increase meaningfully when adding measured $\mathrm{HR}_{\max }$ and $\mathrm{VO}_{2 \max }$ into the FB software $\left(\mathrm{EE}_{3}\right)(\mathrm{r}=0.722)$. The correlations between EE measures during low-intensity activity were not as strong as would be desired, however support for the similarity between the measures comes from the fact that no significant differences were detected using paired t-tests, and there were only $0.66 \%, 4.09 \%$, and $6.13 \%$ differences between the means of $\mathrm{EE}_{\mathrm{IC}}$ and $\mathrm{EE}_{1}, \mathrm{EE}_{2}$, and $\mathrm{EE}_{3}$ respectively. Based on these results, the use of $\mathrm{HRV}$-analysis in place of IC during low-intensity activity is warranted, however it is recognized that EE outputs are likely slightly less than actual values. However, the differences do not appear to be large enough to alter the overall interpretation of the energy demands of the activity being analyzed. These results are consistent with the findings of Montgomery, et al. [14], who also indicated slight underestimation of EE from HRV analysis in comparison to that obtained from IC during moderate to high intensity activity.

During maximum intensity activity, intraclass correlations for the $\mathrm{VO}_{2 \max }$ test between $\mathrm{EE}$ estimations from the $\mathrm{FB}$ software and those obtained from gas-exchange analysis 
were strong (see Figure 2) and provide support for the use of HRV-based EE estimation, in place of IC, for high-intensity activities. Interestingly, the correlation between $\mathrm{EE}_{1}$ and $\mathrm{EE}_{\mathrm{IC}}(\mathrm{r}=0.844)$ was essentially the same as that which used the predicted $\mathrm{VO}_{2 \max }$ from the basic level of analysis $\left(\mathrm{EE}_{2}\right)$ $(r=0.850)$. This indicates that allowing the software to perform the analysis with just baseline participant information and predicted $\mathrm{HR}_{\max }$ is a suitable option for high-intensity activity analysis. If however measured $\mathrm{HR}_{\max }$ and $\mathrm{VO}_{2 \max }$ values are available, they should be used as the software analysis with those values included $\left(\mathrm{EE}_{3}\right)$ provides a stronger correlation with IC $(r=0.973)$. Paired t-tests between the HRV analysis conditions and IC showed no significant differences, and there were only $5.69 \%, 1.17 \%$ and $0.39 \%$ differences between the means of $\mathrm{EE}_{\mathrm{IC}}$ and $\mathrm{EE}_{1}$, $\mathrm{EE}_{2}$, and $\mathrm{EE}_{3}$ respectively, indicating that $\mathrm{HRV}$-analysis is a viable substitute for IC during high-intensity activities without the need for individual device calibration beyond baseline measures.

During free-living activity, the FB analysis conditions correlated strongly amongst themselves indicating that similar EE measures would be obtained whether using basic participant information or performing testing to obtain $\mathrm{HR}_{\max }$ and $\mathrm{VO}_{2 \max }$ values. This point is further supported by the negligible difference $(4.2 \%)$ between the baseline analysis condition $\left(\mathrm{EE}_{1}\right)$ and that using measured $\mathrm{HR}_{\max }$ and $\mathrm{VO}_{2 \max }$ values $\left(\mathrm{EE}_{3}\right)$. Because of the strong relationship found between EE measures from all HRV analysis conditions and IC, across the full range of physical intensities, we were able to assume that the HRV-based EE measures for daily free-living activity were sufficiently close to those that would be obtained if IC was a viable option for free-living activity. Based on the marginal differences between the EE measurements across the difference analysis conditions, the use of only baseline information, without the need to perform testing to obtain $\mathrm{HR}_{\max }$ and $\mathrm{VO}_{2 \max }$ values, is supported.

\section{Conclusions}

The results of this study confirm that the use of HRV-based EE estimation without the need to perform individual device calibration beyond baseline participant measures (age, height, weight, $\mathrm{HR}_{\text {rest }}, \mathrm{HR}_{\max }$, activity level) can be used. HRV-based EE measures improve in relation to IC-based measures when measured $\mathrm{HR}_{\max }$ and $\mathrm{VO}_{2 \max }$ values are included, therefore with individuals and populations where the testing to obtain these measures is not a health risk it is advised that they are obtained and used for analysis to ensure the best possible accuracy in relation to IC. The ability of HRV analysis to provide long-term time/activity specific EE monitoring during free-living activity is its most appealing advantage over IC. Additionally, the information it provides is useful in terms of exercise prescription, health maintenance, physical capacity assessment, and activity monitoring $[1,2,8,18]$. Typically these applications are relevant individuals where the tests to obtain $\mathrm{HR}_{\max }$ and $\mathrm{VO}_{2 \max }$ measures would be contraindicated [4]. Because of this, verifying that accurate EE measures can be obtained using baseline participant information is of the utmost importance.

Whereas the study by Montgomery et al. [14] was conducted in well-trained athletes, this study used non-elite athlete subjects to draw conclusions regarding the accuracy of HRV-based EE estimations in a general population of individuals. Thus, in addition to justifying the use of HRV monitoring in at-risk populations and individuals, we have shown that this technology is appropriate for use in healthy, working, non-elite athlete populations and individuals wherein HRV monitoring is useful for the same purposes. In these cases however, it is advised that if time and resources allow, the necessary testing to obtain the values that improve accuracy should be performed. It should be noted that based on the low-intensity results, underestimation in HRV-based EE estimations may occur in daily free-living usage during sedentary and sleep periods, and this should be considered when interpreting the EE measures in free-living conditions. The underestimation however is not clinically significant and the data may still be used to provide useful recommendations. Further technological development and research into how to improve EE estimations under these conditions is recommended. More specifically, future research should be conducted to determine how the software algorithm might be recalibrated to even more accurately estimate EE across the full range of physical intensities. Ultimately, the benefits inherent in this technology outweigh its limitations and the results show that EE measures obtained through HRV data analysis in FirstBeat SPORT software can be used with confidence.

\section{Acknowledgements}

This study received no financial support. The authors would like to thank all of the participants who generously donated their time and consented to participate in this study. We are also grateful to Owen Montpellier who assisted with the data collection for this research. All authors reviewed and provided feedback on the manuscript prior to approving the final draft.

\section{Conflict of Interest}

The authors declare no conflicts of interest.

\section{Author Contributions}

$\mathrm{SD}, \mathrm{SR}$, and $\mathrm{AG}$ were involved in the conception and design of the study KK and ML recruited participants and collected the data. AR was responsible for data/statistical analysis and interpretation, and drafting of the article manuscript. KK, ML, SR, AG, and SD were involved in 
editing of the manuscript. All authors read and approved the final manuscript.

\section{REFERENCES}

[1] Acharya, U. R., Joseph, K. P., Kannathal, N., Min Lim, C., \& Suri, J. S. (2006). Heart rate variability: a review. Medical \& Biological Engineering \& Computng, 44 (12), 1031-1051.

[2] Achten, J., \& Jeukendrup, A. E. (2003). Heart Rate Monitoring: Applications and Limitations. Sports Medicine , 33 (7), 517-538.

[3] Ainslie, P. N., Reilly, T., \& Westerterp, K. R. (2003). Estimating Human Energy Expenditure. Sports Medicine , 33 (9), 683-698.

[4] Canadian Society for Exercise Physiology. (2014). PAR-Q Forms. Retrieved Aug 7, 2014, from CSEP: http://www.csep.ca/english/view.asp? $\mathrm{x}=698$

[5] Crouter, S., Albright, C., \& Bassett Jr., D. (2004). Accuracy of Polar S410 Heart Rate Monitor to Estimate Energy Cost of Exercise. Medicine \& Science in Sports \& Exercise , 36 (8), 1433-1439.

[6] Dannecker, KL, Szaonova NA, Melanson, EL, Sazonov ES, Browing RC. A comparison of energy expenditure estimation of several physical activity monitors. Medicine \& Science in Sports and Exercise. 2013;45(11):2105-2112.

[7] Ergodan, A., Cetin, C., Karatosun, H., Lüfti Baydar, M. Accuracy of the Polar S810TM heart rate monitor and the Sensewear Pro ArmbandTM to estimate energy expenditure of indoor rowing exercise in overweight and obese individuals. Journal of Sports Science and Medicine. 2010;9:508-516.

[8] Firstbeat Technologies Ltd. (2007). An Energy Expenditure Estimation Method Based on Heart Rate Measurement. Jyväskylä, Finland: Firstbeat Technologies Ltd.

[9] Fuller, Z., Horgan, G., O'Reilly, L., Ritz, P., Milne, E., \& Stubbs, R. (2008). Comparing different measures of energy expenditure in human subjects resident in a metabolic facility. European Journal of Clinical Nutrition , 62, 560-569.

[10] Howley, T., Bassett, D., \& Welch, H. (2005). Criteria for maximal oxygen uptake: review and commentary. Medicine \& Science in Sports \& Exercise , 27, 1292-1301.

[11] Jakicic, J. M., Winters, C., Lagally, K., Ho, J., Robertson, R. J., \& Wing, R. R. (1999). The accuracy of the TriTrac-R3D accelerometer to estimate energy expenditure. Medicine \& Science in Sports \& Exercise , 31 (5), 747-754.

[12] Levine, J. A. (2005). Measurement of energy expenditure. Public Health Nutrition , 8 (7a), 1123-1132.

[13] Macfarlane, D. J. (2001). Automated Metabolic Gas Analysis Systems: A Review. Sports Medicine , 31 (12), 841-861.

[14] Montgomery, P., Green, D., Etxebarria, N., Pyne, D., Saunders, P., \& Minahan, C. (2009). Validation of heart rate monitor-based predictions of oxygen uptake and energy expenditure. Journal of Strength and Conditioning Research , 23 (5), 1489-1495.

[15] Pollock, M., Gaesser, G., Butcher, J., Després, J., Dishman, R., Franklin, B., et al. (1998). ACSM position stand: The recommended quantity and quality of exercise for developing and maintaining cardiorespiratory and muscular fitness, and flexibility in healthy adults. Medicine \& Science in Sports \& Exercise , 30, 975-991.

[16] Rennie, K. L., Hennings, S. J., Mitchell, J., \& Wareham, N. J. (2001). Estimating energy expenditure by heart-rate monitoring without individual calibration. Medicine \& Science in Sports \& Exercise , 33 (6), 939-945.

[17] Tanaka, H., Monahan, K. D., \& Seals, D. R. (2001). Age-Predicted Maximal Heart Rate Revisited. Journal of the American College of Cardiology , 37 (1), 153-156.

[18] Task Force of The European Society of Cardiology and The North American Society of Pacing and Electrophysiology. Heart rate variability: Standards of measurement, physiological interpretation, and clinical use. European Heart Journal. 1996;17:354-381.

[19] Taylor, R. (1990). Interpretation of the Correlation Coefficient: A Basic Review. Journal of Diagnostic Medical Sonography, 6 (1), 35-39. 